\title{
Viajeros a América del Sur
}

\author{
Susana Cristina Lloveras
}

\begin{abstract}
Hospital F. J. Muñiz. Buenos Aires, Argentina

Área de Medicina del Viajero del Centro Municipal de Patologías Regionales Argentinas y Medicina Tropical (CEMPRA-MT).

La autora declara no tener conflictos de interés.

Recibido: 14 de septiembre de 2011

Aceptado: 5 de octubre de 2011
\end{abstract}

Correspondencia a: Susana Cristina Lloveras slloveras@intramed.net

\section{Travellers to South America}

The geography, tourist attractions and the multiple sites of historical and cultural interest make South America as an important destination chosen by travelers. The continent has a wide climatic variation from north to south, making exposure to risk different between the tropics and the temperate or cold regions. In the countries of tropical South America, the greatest risk is associated with the possibility of acquiring vector-borne diseases, like yellow fever, dengue, malaria and leishmaniasis. The risk of acquiring traveler's diarrhea and food-borne illness is similar across the continent, with some variations according to country and to visit urban or rural areas. Rabies, pertussis and diphtheria have appeared as epidemics in several countries and other diseases such as rickettsiosis, hantavirosis and viral encephalitis have expanded their distribution. The geographic and epidemiological diversity of South America, promotes a challenge for travel medicine specialists because during the pre-travel advice they have to take in account the kind of trip, traveller's medical history, exposure to risk and the dynamics of endemic emerging and reemerging diseases in the region.

Key words: travellers medicine, South America, risk, vector borne diseases, foodborne diseases, zoonoses.

Palabras clave: Medicina del viajero, Sudamérica, riesgo, enfermedades mediadas por vectores, enfermedades transmitidas por alimentos, zoonosis.

\section{Introducción}

A mérica del Sur es uno de los más extensos continentes del mundo y se encuentra delimitado por el Mar Caribe hacia el norte, el Océano Atlántico hacia el este, y el Océano Pacífico al oeste. Tiene una superficie total de 17.814 millones de kilómetros cuadrados y se encuentra asentado sobre la Placa de Sudamérica, por debajo de la cual se desliza la Placa de Nazca ${ }^{1}$.

El relieve de América del Sur se puede dividir en tres sectores: la cordillera de los Andes, las tierras bajas del interior, y el escudo continental. Los Andes es la cadena montañosa más larga del mundo que recorre el continente de norte a sur y se ramifica en cordilleras que encierran valles como la Depresión intermedia y el Valle del Cauca, en Colombia, y altiplanos como el Altiplano andino que cubre una región seca entre Bolivia, Perú, Argentina y Chile. El pico más alto de los Andes es el Aconcagua, con 6.962 msnm. La tierras bajas son las tres llanuras: del Orinoco, amazónica y chacopampeana con tres cuencas hidrográficas principales y orientadas al Atlántico: ríos Amazonas; Orinoco, Paraná-La Plata. El escudo continental se separa en tres secciones desiguales: el macizo de Brasilia, el macizo Guayano-venezolano, y el macizo Patagónico. Esta gran variedad de altitud produce una diversidad climática y ecológica, que es una característica prominente de la geografía de América del Sur. Más de 75\% de su territorio se encuentra dentro de la zona tropical y debido a sus alturas andinas tiene extensas zonas templadas y frías en las proximidades del Ecuador ${ }^{1}$.

Está integrado por 12 países independientes: Argentina, Bolivia, Brasil, Colombia, Chile, Ecuador, Guyana, Paraguay, Perú, Surinam, Uruguay y Venezuela, y una dependencia de Francia: Guayana Francesa.

La diversidad de la geografía, los atractivos turísticos y los múltiples sitios de interés histórico cultural, hacen que América del Sur sea un destino elegido por los viajeros. Las motivaciones para visitar este continente son muy variadas, como por turismo, negocios, trabajo, estudio, participación en eventos deportivos o como miembros de organizaciones no gubernamentales (ONG) o religiosas, entre otras. También hay que considerar los migrantes regionales y los que regresan a sus países luego de haber emigrado, para visitar familiares y amigos.

Según la Organización Mundial de Turismo, las llegadas de turistas internacionales crecieron, con respecto al año anterior, aproximadamente 5\% durante los primeros meses de 2011. Entre enero y junio de este año, el número total de llegadas se elevó a 440 millones, 19 millones más que en el mismo período de 2010. Las Américas registraron un crecimiento ligeramente superior a la media mundial, siendo especialmente notables los resultados de América del Sur que creció más de $15 \%{ }^{2}$.

El continente tiene una amplia variación climática de norte a sur, lo que hace que la exposición al riesgo sea diferente, ya que hay países ubicados en forma completa 
en el trópico y otros en áreas templadas o frías. Estas diferencias climáticas permiten hacer una división entre América del Sur tropical y templada, donde los riesgos para los viajeros son diferentes de acuerdo a las enfermedades presentes en cada región.

En América del Sur tropical se incluyen los siguientes países: Bolivia, Brasil, Colombia, Ecuador, Guayana Francesa, Guyana, Paraguay, Perú, Surinam y Venezuela.

América del Sur templada incluye Argentina, Chile y Uruguay.

\section{Enfermedades transmitidas por agua y alimentos}

La diarrea del viajero y otras enfermedades que se adquieren por el consumo de agua y alimentos contaminados (ETAs), son las enfermedades más frecuentemente adquiridas por los viajeros a la región. La diarrea del viajero puede ser causada por bacterias (80-90\%), parásitos (10\%), virus (5-8\%), y toxinas presentes en los alimentos. La diarrea bacteriana causada por Escherichia coli enterotoxigénica es la más frecuente, seguida por Escherichia coli enteroagregativa y otras bacterias (Campylobacter jejuni, Shigella sp, Salmonella sp y otras variedades enteropatogénicas de E. coli), virus (norovirus, rotavirus y astrovirus) y protozoos (Giardia sp, Cryptosporidium sp y Entamoeba histolytica $)^{3}$.

Los riesgos están relacionados al consumo de agua o alimentos contaminados y a la preparación y manipulación no higiénica de los mismos.

En todos los países existe riesgo de adquisición de hepatitis $A$, pero el mismo es variable entre las áreas urbanas y rurales. La hepatitis A es una de las enfermedades inmunoprevenibles más frecuente en los viajeros. Las áreas geográficas se caracterizan por bajo, intermedio o alto nivel de endemia por el virus de la hepatitis A y estos niveles se correlacionan con las condiciones sanitarias y de higiene de cada área. La mayoría de los países de América del Sur se consideraron siempre de endemia alta o intermedia para la hepatitis A, pero en los últimos años estudios de seroprevalencia y de incidencia de enfermedad, realizados en varios de ellos, posteriormente a la incorporación de la vacuna a los calendarios oficiales en la infancia, muestran cambios en los patrones epidemiológicos. En la actualidad la mayoría de los países de la región se han desplazado a regiones con condiciones de endemia intermedia o baja ${ }^{4}$.

Otra ETA frecuente en la región es la fiebre tifoidea, la cual sigue siendo un problema de salud pública en algunos países donde hay deficiencias de saneamiento ambiental básico. Algunos de los países con más alto riesgo para la adquisición de la enfermedad se encuentran entre los que conforman América del Sur tropical, por lo cual en los viajeros por largos períodos de tiempo, aventureros, sin itinerarios fijos o que recorrerán áreas rurales, hay que considerar la vacunación contra fiebre tifoidea. La vacuna no es $100 \%$ efectiva por lo cual los viajeros vacunados no deben abandonar las precauciones en el consumo de agua y alimentos.

En América del Sur templada, Chile tuvo la última epidemia de fiebre tifoidea entre 1976-1985 y el número de casos fue descendiendo paulatinamente hasta caer abruptamente entre 1991-1992, debido a las medidas de salud pública tomadas para interrumpir la transmisión de Vibrio cholerae durante la epidemia de cólera que afectaba

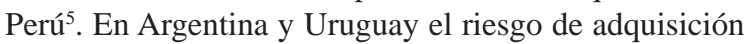
de la enfermedad es bajo.

El cólera, infección diarreica aguda causada por la ingestión de alimentos o agua contaminados con el bacilo $V$. cholerae, afecta entre 3 millones y 5 millones de personas por año y provoca entre 100.000 y 120.000 muertes. Tiene un breve período de incubación, que varía entre dos horas y cinco días, por lo cual los brotes epidémicos muchas veces aparecen de forma explosiva. La pandemia de cólera causada por V. cholerae 01 toxígeno, biotipo El Tor, llegó a América del Sur en $1991^{6}$. A excepción del Uruguay, todos los países de América del Sur fueron afectados por la enfermedad hacia 1993. Luego de esta epidemia, en el 2005, solamente Brasil, Colombia y Ecuador reportaron casos. El brote reciente de cólera registrado en Haití, luego del terremoto producido en enero de 2010 se extendió a República Dominicana y generó, en enero de 2011, varios casos de la enfermedad en viajeros que regresaron a Venezuela, luego de haber asistido a una fiesta en Santo Domingo ${ }^{7}$.

Otras enfermedades que pueden adquirirse por el consumo de agua y alimentos son la brucelosis, triquinosis y fasciolasis pero son poco frecuentes en viajeros. Existen parasitosis asociadas al consumo de pescado, mariscos y crustáceos crudos que son frecuentes en el área asociadas a costumbres culinarias de algunos países. Dentro de estas parasitosis hay que considerar la paragonimiosis, endémica en Perú y Ecuador, la gnathostomiasis que se ha convertido en un problema de salud pública en muchos países, asociada al consumo de ceviche, al igual que la difilobotriasis en el sur de Chile.

Si bien la forma de transmisión vectorial de la enfermedad de Chagas es la más frecuente, existe la posibilidad de transmisión por vía oral a través de la ingesta de triatominos triturados, de frutas o partes aéreas de vegetales contaminadas con heces de éstos y de secreción anal u orina de marsupiales infectados. Los alimentos más fre- 
cuentemente asociados a transmisión de Chagas por vía oral son: jugo de caña (Brasil); jugo de açaí (Brasil), jugo de guayaba (Venezuela) y vino de palma en Colombia ${ }^{8}$.

El riesgo de adquisición de diarrea del viajero y de otras ETAs se reduce con el lavado frecuente de manos con agua y jabón; consumo de agua potable, hervida o potabilizada, bebidas envasadas; frutas y verduras lavadas con agua potable y peladas; alimentos (carnes, mariscos y verduras) cocidos y lácteos pasteurizados. Es recomendable que los viajeros no agreguen hielo a las bebidas, eviten comer en puestos callejeros y no consuman productos de procedencia casera sin controles sanitarios (quesos, salames u otros embutidos y conservas).

\section{Enfermedades vectoriales}

Muchas enfermedades se transmiten por la picadura de artrópodos infectados como mosquitos, moscas, pulgas, garrapatas y piojos. Para la mayoría de esta enfermedades no hay vacunas disponibles y los viajeros deben protegerse de las picaduras de artrópodos utilizando ropa clara que cubra los brazos y las piernas, especialmente durante la mañana y la tarde, mientras realicen actividades al aire libre; aplicar un repelente de insectos sobre la piel ( $N, N$-dietil-meta-toluamida,DEET 25-50\%); usar ropa o mosquiteros impregnados en permetrina al 3\% e insecticidas de ambiente durante la noche. También los viajeros deben ser advertidos para inspeccionarse minuciosamente la cabeza, el cuerpo y sus prendas de vestir en búsqueda de garrapatas, después de realizar actividades al aire libre y remover las garrapatas adheridas mediante el uso de pinzas.

\section{América del Sur tropical}

El paludismo o malaria tiene una amplia distribución en los países de América del Sur tropical. Plasmodium vivax causa aproximadamente $74 \%$ de los casos de paludismo de la región, $P$. falciparum el 25,6\% y P. malariae, menos de $0,4 \%$ de los casos. Esta proporción se mantiene en los países que comparten la selva amazónica, a excepción de aquellos que son parte del Escudo Guyanés (Guayana Francesa, Guyana y Surinam), donde la especie dominante es $P$. falciparum.

Entre 2000 y 2007, 15 países en la región de América presentaron reducción de casos de paludismo, y seis países aumentaron el número, de los cuales cuatro se encuentran en América del Sur tropical: Colombia, Venezuela, Guyana y Perú9. Para los viajeros a esta región el riesgo de adquirir malaria en los destinos turísticos más populares es bajo y generalmente los casos son por
P.vivax. Algunos estudios han demostrado que el riesgo de los efectos adversos de la quimioprofilaxis podría ser significativamente mayor al riesgo real de adquisición de malaria, por lo cual hay que valorar claramente la necesidad de la misma. Ante la aparición de síntomas de la enfermedad, probablemente la consulta médica precoz y el auto-tratamiento de emergencia serían más adecuados. En los viajeros a Guayana Francesa y Surinam, es necesaria la quimioprofilaxis ya que existe elevado riesgo de adquirir la enfermedad en la mayor parte de sus territorios ${ }^{10}$.

La fiebre amarilla, enfermedad infecciosa aguda causada por un virus del género Flavivirus, y transmitida por la picadura de mosquitos, es mantenida en América del Sur por transmisión en un ciclo selvático entre primates cuyo vector es Haemagogus spp y el ser humano es ocasionalmente infectado al introducirse en áreas de selva. En el ciclo urbano de transmisión, el virus es transmitido desde un humano infectado a un susceptible a través de la picadura del mosquito hembra Aedes aegypti que se encuentra preferentemente en zonas urbanas. Los informes oficiales de incidencia de fiebre amarilla, reportan 50-120 casos por año en América del Sur durante la última década, y probablemente el número real de casos esté subestimado ${ }^{11}$.

Los viajeros a América del Sur podrían tener diez veces menos riesgo de adquirir la enfermedad que los viajeros a África, porque la tasa de transmisión en el ciclo selvático es más baja ${ }^{12}$. Sin embargo, el riesgo de adquisición depende de múltiples factores como época del año, itinerario y actividades a realizar, densidad vectorial y circulación del virus de la fiebre amarilla. No existe un tratamiento específico para la fiebre amarilla por lo cual la vacunación es la medida de prevención tanto para los habitantes de los países endémicos como para los viajeros.

Es muy importante valorar el riesgo de adquisición de esta enfermedad en los viajeros e indicar la vacunación oportunamente, ya que se han reportado varios casos de fiebre amarilla en personas no inmunizadas que visitaron regiones endémicas en América del Sur ${ }^{13-15}$. Las áreas de riesgo en América del Sur (tropical y templada), donde se recomienda que los viajeros que las visiten se vacunen contra fiebre amarilla, pueden visualizarse en el mapa de la Organización Mundial de la Salud 2010 ${ }^{16}$.

El dengue es endémico en la región de las Américas y en los últimos 20 años ha tenido una incidencia en ascenso con picos epidémicos cada vez mayores que se reiteran cada 3 ó 5 años en forma regular. Los viajeros tienen riesgo de adquirir esta virosis al visitar áreas de riesgo dentro del continente. En la actualidad, se encuentran los cuatro serotipos de virus dengue circulando en la región y hasta la semana epidemiológica 33 se han reportado miles de casos de dengue en los países de América del Sur, como así también cuadros de dengue grave y muertes. La 
información por países está disponible en la Organización Panamericana de Salud ${ }^{17}$.

La leishmaniasis es una zoonosis provocada por protozoos que pertenecen al género Leishmania, familia Tripanosomatidae. Se transmite de los animales reservorios a los seres humanos a través de la picadura de Phlebotomus del género Lutzomia. Existen dos formas clínicas: tegumentaria y visceral. La leishmaniasis cutánea del Nuevo Mundo es causada por múltiples especies que incluyen los complejos $L$. braziliensis y el L. mexicana, mientras que la forma visceral es provocada por L.infantum/chagasi.

La leishmaniasis tegumentaria al regreso de un viaje por Latinoamérica, es uno de los motivos de consulta más frecuente en los viajeros. Los países de mayor riesgo para adquirir esta enfermedad son Brasil, Perú (Parque Nacional Manú) y Bolivia (Parque Nacional Madidi). También existe riesgo en otros países que integran la Cuenca Amazónica.

La leishmaniasis visceral se encuentra principalmente en Brasil y Paraguay.

Otras infecciones transmitidas por vectores son las infecciones por Rickettsias sp que generalmente son transmitidas desde los hospederos-reservorios animales al humano a través de la picadura de una amplia variedad de artrópodos como los piojos, las pulgas y las garrapatas. Cada uno de estos artrópodos, está asociado con una o varias enfermedades rickettsiales y mantienen ciclos zoonóticos en la naturaleza. La Fiebre Manchada de las Montañas Rocosas causada por Rickettsia rickettsii ha sido descrita en dos países de América del Sur tropical (Brasil y Colombia) y es transmitida por diversas especies de “garrapatas duras”. El principal vector en Sudamérica es Amblyomma cajennense aunque existen otras especies de garrapatas capaces de transmitirla. Brasil es el país que presenta el mayor número de casos letales por año, donde la letalidad en el Estado de San Pablo alcanza valores cercanos a $30 \%{ }^{18}$.

Rickettsia parkeri ha sido detectada infectando a la garrapata Amblyomma triste en Brasil pero hasta el momento no se han reportado casos humanos ${ }^{19}$.

El tifus epidémico o tifus transmitido por piojos, causado por $R$. prowazekii, ha sido reportado en la tierras altas de Bolivia y Perú.

En América del Sur se han descrito numerosos brotes de enfermedad por el virus de Oropouche en comunidades rurales y urbanas de Brasil, Ecuador y Perú. El virus Oropouche se mantiene en la naturaleza en dos ciclos distintos. Uno silvestre, donde los reservorios son animales silvestres, posiblemente primates, perezosos y ciertos artrópodos con los mosquitos como vectores y, un ciclo epidémico urbano, en la cual la infección se mantiene vector-hombre-vector, con el ser humano como hospedero principal. Los brotes por virus Oropouche registrados en los últimos diez años han tenido lugar principalmente en la región amazónica. En el año 2010 se produjo un brote epidémico de esta enfermedad en Perú, en el Departamento de San Martín ${ }^{20}$.

La fiebre Mayaro es una zoonosis producida por un arbovirus, endémico en regiones tropicales de América del Sur y transmitido por mosquitos Haemagogus spp. El virus ha sido aislado en humanos, vertebrados silvestres y mosquitos en Bolivia, Brasil, Colombia, Guyana, Guayana Francesa, Perú y Surinam. En Venezuela, en el Estado de Portuguesa, se produjo un brote epidémico durante el año $2010^{21}$.

La encefalitis equina venezolana (EEV) es provocada por un virus del género de los Alfavirus, familia Togaviridae y transmitida a través de la picadura de mosquitos infectados. Es enzoótica en bosques húmedos tropicales y áreas pantanosas de América de Sur. Aparece en forma de epizootias, principalmente en la zona septentrional y occidental de América del Sur. En 1995 se registró un brote de EEV en humanos que afectó a siete estados en Venezuela y en el departamento de la Guajira en Colombia con más de 400.000 casos registrados y 46 defunciones entre ambos países ${ }^{22}$.

La enfermedad de Chagas o tripanosomiasis americana es causada por un protozoo flagelado, Trypanosoma cruzi y transmitida por insectos triatominos de la familia Reduviidae. Es una enfermedad endémica en varios países de América del Sur pero en alguno de ellos, como por Brasil la transmisión se ha interrumpido a través de los programas de erradicación. El riesgo para los viajeros es mayor en áreas rurales, por lo cual es recomendable que eviten pernoctar en viviendas de barro, adobe o paja. También es recomendable la utilización insecticidas ambientales y métodos de barrera (cobertores de cama con insecticidas) en lugares riesgo $0^{23}$.

La oncocercosis es una enfermedad parasitaria crónica causada por filarias Onchocerca volvulus y transmitida por varias especies de insectos del género Simulium que crecen en los riachuelos torrentosos y limpios. Ocasiona daños en la piel (dermatitis papular prurítica y nódulos subcutáneos), linfadenitis y puede llegar a producir graves alteraciones en los ojos, hasta ceguera. La oncocercosis es endémica en algunos países y no se ha podido eliminar aún en determinadas zonas de Brasil y Venezuela donde los esfuerzos de erradicación están en curso.

La enfermedad de Carrión, fiebre de la Oroya o verruga peruana es una enfermedad infecciosa cuyo agente etioló- 
gico es la bacteria Bartonella bacilliformis y transmitida por flebótomos del género Lutzomyia. El mayor foco endémico se encuentra en los valles interandinos de Perú, entre 500 a 3.200 metros sobre el nivel del mar, Ecuador, y el suroeste de Colombia.

La filariasis linfática es endémica en Guyana y Brasil, donde se han intensificado los esfuerzos para eliminarla. Surinam está a la espera de la validación de la eliminación de la enfermedad.

La miasis forunculoide por Dermatobia hominis (“mosca zumbadora”) es una patología frecuentemente adquirida por los viajeros a la mayoría de los países de América del Sur, especialmente aquellos con clima tropical o subtropical.

\section{América del Sur templada}

Existe un área limitada de transmisión de malaria por $P$. vivax en Argentina y durante la última década se ha producido un promedio menor a 300 casos anuales. La transmisión es principalmente estacional y afecta a poblaciones en áreas selváticas y rurales. Existe un área endémica en la región noroeste, en las áreas tropicales de las Provincias de Salta y Jujuy, con incidencia más o menos constante de casos. En la región noreste, en la Provincia de Misiones, hay aparición de casos de paludismo en forma epidémica en relación a los brotes que ocurren en Paraguay y Brasil. La malaria en Argentina es una enfermedad en vías de eliminación de acuerdo al Programa de Malaria de OPS/OMS.

El virus de la fiebre amarilla circula en los monos y los mosquitos en las regiones selváticas a lo largo de los ríos Iguazú y Paraná. Todos los viajeros, incluso los que tengan una estadía breve en el área, deben ser vacunados. En la actualidad, Brasil y Argentina no requieren certificado internacional de vacunación a los viajeros. La vacuna contra fiebre amarilla, sólo está recomendada para viajeros mayores de 9 meses de edad que viajen a la Provincia de Corrientes (Berón de Astrada, Capital, General Alvear, General Paz, Itatí, Ituzaingó, Paso de los Libres, San Cosme, San Martín, San Miguel, Santo Tomé) y Misiones (todos los departamentos) y especialmente los que visitarán las Cataratas del Iguazú ${ }^{4}$.

En Argentina, durante la última década, se han registrado casos de dengue autóctonos vinculados a los serotipos DEN- 1, 2 y 3 en las Provincias de Salta y Jujuy, y se han registrado casos con los serotipos DEN 1 y 3 en las Provincias de Formosa, Misiones y Corrientes. No se han notificado casos de serotipo DEN 4. El dengue en Argentina es epidémico, y la ocurrencia de casos se restringe a los meses cálidos (noviembre a mayo). Durante el año 2009 se produjo un brote de dengue por el serotipo DEN 1 que afectó a un mayor número de provincias y se registraron casos autóctonos en Provincia de Buenos Aires, Catamarca, Ciudad Autónoma de Buenos Aires, Córdoba, Chaco, Entre Ríos, La Rioja, Santa Fe, Santiago del Estero y Tucumán. Durante el trascurso de 2011 el único lugar con circulación de virus dengue-serotipo 1 fue el norte de la Provincia de Santa Fe (Romang, Malabrigo y Avellaneda). Hasta junio de 2011 no hay circulación de virus dengue en Argentina ${ }^{25}$.

En la Isla de Pascua (Chile) en el año 2002 se produjo un brote de dengue por el serotipo DEN-1, que afectó aproximadamente a $80 \%$ de la población y en los años subsiguientes se confirmaron muy pocos casos no superando los 30 anuales. En el año 2010 no se reportó caso alguno. Todos los casos correspondieron al serotipo DEN-1, exceptuando tres casos del año 2009 que correspondieron al serotipo DEN-4. Hasta la semana epidemiológica $N^{\circ} 45$ de 2011, se ha confirmado sólo un caso de fiebre dengue autóctono en Isla de Pascua ${ }^{26}$.

Uruguay es el único país sin transmisión autóctona de dengue a pesar que Aedes aegypti fue detectado en el país durante el verano y otoño de $1997^{27}$.

Hay transmisión de leishmaniasis cutánea y cutáneomucosa en las provincias del norte y nordeste de Argentina (Salta, Jujuy, Formosa, Chaco, Misiones, Corrientes, Santiago del Estero, Tucumán y Catamarca). Existe riesgo de adquirir leishmaniasis visceral en las Provincias de Misiones y Corrientes ${ }^{28}$.

La encefalitis de San Luis (SLEV), arbovirosis transmitida por la picadura de mosquitos produjo un brote humano epidémico durante el año 2005 en la Provincia de Córdoba (Argentina) y se identificaron 47 casos predominantemente en personas de 60 años o más. El brote se inició en el mes de enero, con dos picos en los meses de febrero y marzo, y finalizó en el mes de mayo, con la ocurrencia de 9 casos fatales ${ }^{29}$. Entre los años 2006 y 2008, la intensificación de la vigilancia epidemiológica, permitió la detección de 33 casos humanos por el virus SLE en diversas Provincias de Argentina. En 2010, se notificó un aumento de la detección de casos en la Ciudad Autónoma de Buenos Aires, Provincia de Buenos Aires, Chaco, Corrientes, Córdoba, Entre Ríos, Santa Fe y Tucumán $^{30}$. En los primeros meses de 2011 se notificó un brote de la enfermedad en la provincia de San Juan.

La enfermedad de Chagas está controlada en aéreas rurales y el riesgo a los viajeros se estima insignificante. Se recomienda evitar pernoctar en viviendas de barro, adobe o paja. Utilizar insecticidas ambientales y métodos de barrera (cobertores de cama con insecticidas) en lugares con riesgo. 
Rickettsia parkeri, se ha identificado recientemente en las garrapatas Amblyomma triste en varios países de América del Sur, incluyendo Argentina y Uruguay donde causan rickettsiosis en los seres humanos ${ }^{31,32}$.

También en la provincia de Jujuy, Argentina, se ha descripto Fiebre Manchada de las Montañas Rocosas causada por $R$. rickettsii ${ }^{33,34}$.

\section{Infecciones zoonóticas}

En la mayor parte de los países que conforman América del Sur tropical hay riesgo de adquirir rabia, no sólo transmitida por animales domésticos no vacunados sino también en áreas de selva por murciélagos. Según la Organización Panamericana de la Salud (OPS) los países con mayor riesgo para la adquisición de rabia humana son: Bolivia, Ecuador, Brasil y Perú. En Bolivia actualmente existe una epidemia de rabia canina y humana, con el mayor número de casos reportados en Santa Cruz de la Sierra pero también en Cochabamba y en otras áreas ${ }^{35}$.

Es importante valorar la necesidad de vacunación pre-exposición para rabia, especialmente en viajeros que visitarán áreas con epidemias en curso o regiones selváticas. Entre los países que han estado libres de rabia canina durante la última década se encuentran Chile y Uruguay. La Argentina integraba esta lista pero en el año 2008 registró un caso de rabia humana luego de 24 años libre de enfermedad.

El síndrome cardio-pulmonar por hantavirus fue documentado en Bolivia, Brasil, Paraguay y también en Chile, Uruguay y Argentina. En este último país, el riesgo de adquirir la enfermedad está presente en tres áreas específicas: región patagónica, en áreas delimitadas de las Provincias de Salta y Jujuy; en un área que comprende el norte de la Provincia de Buenos Aires, Santa Fe y Entre Ríos. En la Provincia de Entre Ríos es donde se concentró el mayor número de casos durante $2011^{36}$. Para evitar la adquisición de la enfermedad hay que evitar el contacto con roedores o sus excretas.

Los virus Machupo (fiebre hemorrágica boliviana), Guanarito (fiebre hemorrágica venezolana), Sabia (fiebre hemorrágica brasileña), y el recientemente descubierto virus Chapare (un solo caso en Bolivia) son agentes etiológicos de fiebres hemorrágicas.

En Argentina hay riesgo de adquisición de fiebre hemorrágica argentina (FHA) o mal de los rastrojos causados por el virus Junin. La zona endémica de la FHA compromete las provincias de Buenos Aires, Córdoba, Santa Fe, Entre Ríos y La Pampa, con una población estimada en riesgo de 5 millones. Si bien la enfermedad no es frecuente en viajeros, se sugiere que las personas que visiten áreas rurales de las provincias de riesgo o realicen tareas laborales (agrícola-ganaderas) se apliquen la vacuna contra fiebre hemorrágica argentina.

Todos los virus que producen las fiebres hemorrágicas anteriormente descritas se transmiten por inhalación de aerosoles de la orina de los roedores, ingestión de alimentos contaminados por ellos, o el contacto directo de la piel con excrementos ${ }^{37}$.

\section{Infecciones asociadas al contacto con suelo y agua}

La esquistosomiasis es una infección parasitaria adquirida a través del contacto con agua dulce en áreas tropicales y subtropicales. Las principales formas de la esquistosomiasis son causadas por cinco especies de trematodes: Schistosoma mansoni, S. japonicum, S. haematobium, S. mekongi y S. intercalatum. Los esquistosomas penetran en el organismo por contacto con aguas superficiales infestadas. La esquistosomiasis intestinal causada por $S$. mansoni tiene lugar América del Sur, en un foco endémico en Brasil, Venezuela y Surinam ${ }^{38}$.

El riesgo de leptospirosis se encuentra ampliamente distribuido en las áreas tropicales y templadas de América del Sur, especialmente luego de período de inundaciones.

La histoplasmosis ha sido reportada en todos los países de la región; paracoccidioidomicosis es endémica en amplias áreas, la mayor transmisión ocurre en Perú, Ecuador, Colombia, Brasil, Uruguay y Argentina. La coccidiodomicosis es más frecuente en Brasil, Colombia, Paraguay, Venezuela, y en áreas focales de Argentina.

Los viajeros a países con climas tropicales y húmedos se encuentran en riesgo de adquirir larva migrante cutánea por Ancylostomas sp al caminar descalzos o tomar contacto con suelos arenosos contaminados con heces de perros o gatos.

La tungiasis por Tunga penetrans o "pulga de arena" es otra ectoparasitosis bastante frecuente de adquirir en los países de América tropical.

\section{Enfermedades de transmisión interhumana y por aerosoles}

La gripe o influenza es la enfermedad inmunoprevenible más frecuente en los viajeros a regiones tropicales y subtropicales de acuerdo a un estudio realizado en Suiza. Los datos del GeoSentinel sobre las infecciones respiratorias en los viajeros, revelaron que la influenza se 
asocia más frecuentemente a los viajes al hemisferio norte durante los meses de diciembre a febrero, en aquellos que viajan para visitar a amigos y familiares y realizan un viaje con una duración de más de 30 días ${ }^{39,40}$. América del Sur presenta diversos tipos de circulación de los virus gripales, en los países templados, la circulación es estacional y limitada a la estación invernal mientras que en los países con clima tropical, los virus circulan durante todo el año, pero con uno o dos picos de actividad que coinciden con las épocas de lluvia. En algunos países existen diferencias en la estacionalidad de la influenza ${ }^{41-44}$.

La incidencia anual de tuberculosis es muy variable entre los países de la región ${ }^{45}$. El riesgo para los viajeros va a depender del tiempo de estadía como así también del destino elegido si se trata de una zona altamente endémica de tuberculosis. Hay pocos estudios que permiten documentar el grado de riesgo y los factores asociados con la adquisición de la infección en viajeros. En muchos países la tuberculosis multi-resistente también se ha convertido en un problema de salud pública y en un riesgo para los viajeros.

La difteria sigue siendo endémica en varias regiones de América del Sur, a pesar de los amplios programas de inmunización implementados. El resurgimiento de la enfermedad en algunos países no está aclarado totalmente. Se cree que estaría relacionado con la introducción de cepas toxigénicas de $C$. diphtheriae de un nuevo biotipo en la población general, además de la baja cobertura con la vacuna en los niños y la ausencia de inmunidad en los adultos $^{46}$. En el año 2010, en Bolivia se reportaron casos de difteria en el Departamento Tarija y durante el 2011, Paraguay reportó un brote epidémico en Asunción ${ }^{47,48}$.

La vacunación antitetánica y antidiftérica debe actualizarse, especialmente en los adultos que no han recibido dosis de refuerzo luego de haber completado el esquema de vacunación de la infancia y adolescencia. Es recomendable que uno de los refuerzos, que deben aplicarse cada 10 años, se realice con la vacuna que tiene el componente pertussis acelular (dTpa) ya que en los últimos años la coqueluche se ha transformado en una enfermedad reemergente en varios países de la región.

\section{Enfermedades transmitidas por sexo, sangre o fluidos corporales}

El SIDA y la infección por VIH se producen en todo el mundo. A finales de 2008, más de 33 millones de personas habían adquirido el VIH / SIDA. El riesgo de infección por el VIH para los viajeros internacionales es generalmente bajo, aunque no está determinado tanto por el destino geográfico como por el comportamiento relacionado con el consumo de drogas y relaciones sexuales sin protección. En los países en desarrollo, pueden existir problemas con el control inadecuado en bancos de sangre lo que aumenta el riesgo de transmisión por transfusión ${ }^{49}$.

El riesgo de infección por virus de hepatitis $B$ para los viajeros internacionales se considera en general bajo, excepto para los que viajan a países donde la prevalencia de la infección crónica por este virus es intermedia o alta, como ocurre en países de la cuenca amazónica. La vacunación contra hepatitis B está recomendada para todas las personas no vacunadas que viajan, por el riesgo de exposición accidental a sangre o fluidos corporales, cortopunzantes y contacto sexual.

\section{Otros riesgos}

En los países de la región, existen otros riesgos a los cuales pueden exponerse los viajeros como aquellos relacionados con los accidentes por animales ponzoñosos terrestres y acuáticos. En áreas rurales, para evitar la mordedura por ofidios, los viajeros deben caminar por los senderos establecidos, utilizar botas de caña alta, no remover ramas o piedras con las manos y llevar a los niños en andas. En el caso de mordedura, no deben intentar capturar el ofidio, no aplicar torniquete y realizar consulta médica inmediata. Las mordeduras de arañas y escorpiones pueden ser muy dolorosas y provocar cuadros de gravedad y muerte, especialmente entre lactantes y niños. Los accidentes pueden ocurrir en el interior del hospedaje por lo que los viajeros deben separar las camas de la pared, sacudir el calzado y ropa antes de usarlos y ante un emponzoñamiento realizar consulta médica.

Las lesiones por peces venenosos e invertebrados marinos son muy frecuentes, fundamentalmente por las actividades acuáticas recreativas y por la popularidad de algunos deportes como surf, buceo y snorkeling. La mayoría de las especies responsables de las lesiones, viven en aguas costeras tropicales pero también en algunos de los ríos que atraviesan el continente e incluyen entre otros, rayas, bagres, pirañas, medusas y erizos de mar. Se debe instruir a los viajeros sobre medidas preventivas y primeros auxilios ante un accidente con fauna acuática.

También puede ocurrir intoxicación secundaria al consumo de moluscos bivalvos, mejillones, ostras, vieiras y almejas que se han alimentado de algas tóxicas. La intoxicación por mariscos ocurre generalmente en asociación con las floraciones de algas o “marea roja”, que se caracteriza por la aparición de manchas en las grandes extensiones de agua de las costas y también de peces muertos o moribundos. Los brotes ocurren periódicamente en Chile y Argentina y se debe asesorar a los viajeros para que no consuman este tipo de alimento en caso de alerta 
por parte de las autoridades sanitarias de los respectivos países. Otra intoxicación es la ciguatera causada por la ingestión de peces e invertebrados marinos que han acumulado en sus tejidos cierta cantidad de toxinas producidas por dinoflagelados, de los cuales la especie más frecuentemente asociada es Gamberdiscus toxicus que provoca enfermedad gastrointestinal, neurológica y cardiovascular. Es una enfermedad muy frecuente en los países próximos al mar Caribe ${ }^{50}$.

Otros riesgos que hay que considerar son los accidentes de tránsito, ya que los datos indican que en la mayor parte de los países la epidemia por traumatismos y muerte asociados a este tipo de accidentes sigue en aumento como así también las situaciones de violencia y conflicto social.

Todos los riesgos mencionados anteriormente son dinámicos de acuerdo a los cambios epidemiológicos regionales y mundiales como así también en relación a fenómenos naturales y socioculturales. Los viajeros, también pueden exponerse a otras amenazas para su salud, en función de sus antecedentes personales, itinerario y tiempo de estadía como así también por las actividades que pueden desarrollar en la amplia y variada geografía de América del Sur (montañismo, buceo, espeleología, turismo aventura, entre otras) para lo cual es indispensable un adecuado asesoramiento previo a la fecha de partida.

\section{Resumen}

La variable geografía, los atractivos turísticos y los múltiples sitios de interés histórico cultural, hacen que América del Sur sea un destino elegido por los viajeros. El continente tiene una amplia variación climática de norte a sur, lo que hace que la exposición al riesgo sea diferente entre las regiones tropicales y las templadas o frías. En los países que conforman América del Sur tropical, el mayor riesgo se asocia a la posibilidad de adquirir enfermedades de transmisión vectorial como fiebre amarilla, dengue, paludismo y leishmaniasis entre otras. El riesgo de adquirir diarrea del viajero y enfermedades de transmisión por alimentos es similar en todo el continente, con algunas variaciones de acuerdo al país y si se visitan áreas urbanas o rurales. Rabia, coqueluche y difteria han aparecido en forma epidémica en varios países y otras enfermedades como rickettsiosis, hantavirosis y encefalitis virales han ampliado su distribución. La diversidad geográfica y epidemiológica de América del Sur, plantea un importante desafío para los especialistas en Medicina del Viajero, ya que para asesorar adecuadamente a los viajeros al continente, hay que considerar no sólo el tipo de viaje, sino también los antecedentes personales, la exposición al riesgo y la dinámica de las enfermedades endémicas, emergentes y reemergentes en la región.

\section{Referencias}

1.- http://www.britannica.com/EBchecked/ topic/555844/South-America (accedido 5 de agosto 2011).

2.- http://media.unwto.org/es/pressrelease/2011-09-07/el-turismo-internacionalmuestra-un-saludable-crecimiento-en-laprimera-mit (accedido 15 de septiembre de 2011).

3.- Shah N, DuPont H L, Ramsey D J. Global etiology of travelers' diarrhea: systematic review from 1973 to the present. Am J Trop Med Hyg 2009; 80 (4): 609-14.

4.- Jacobsen K, Wiersma S. Hepatitis A virus seroprevalence by age and world region, 1990 and 2005. Vaccine 2010; 28 (41): 6653-7.

5.- Wolff M. Changes in the epidemiology of infectious diseases in Chile from 1990 to 2000. Rev Med Chile 2002; 130 (4): 353-62.

6.- Reeves P R, Lan R. Cholera in the 1990s. Br Med Bull 1998; 54 (3): 611-23.

7.- $\quad$ http://promedmail.org/pls/apex/f?p=24 00:1001:4310687202593862::::F2400_ P1001_BACK_PAGE,F2400_P1001_ ARCHIVE_NUMBER,F2400_P1001_USE_ ARCHIVE:1001,20110127.0325,Y (accedido 15 de agosto de 2011).

8.- Pereira, Schmidt F, Guaraldo A, Franco R,
Dias V, Passos L. Chagas’ disease as a foodborne illness. J Food Prot 2009; 72 (2): 441-6.

9.- Plan Estratégico Regional contra la Malaria en las Américas 2006-2010 http://www.paho.org/ Spanish/AD/DPC/CD/mal-reg-strat-plan-06. htm(accedido 20 de agosto de 2011).

10.- Behrens R H, Carroll B, Beran J, Bouchaud O, Hellgren U, et al. for TropNetEurop. The low and declining risk of malaria in travellers to Latin America: is there still an indication for chemoprophylaxis?. Malaria J 2007; 6: 114.

11.- WHO. Yellow fever reported cases. http:// apps.who.int/immunization_monitoring/en/ globalsummary/timeseries/tsincidenceyfe.htm (accedido 20 de agosto de 2011).

12.- Monath TP, Cetron MS. Prevention of yellow fever in persons traveling to the tropics. Clin Infect Dis 2002; 34: 1369-78.

13.- Hall P, Fojtasek M, Pettigrove J, Sisley N, Perdue J, Hendricks K, et al. Fatal yellow fever in a traveler returning from Amazonas. MMWR Morb Mortal Wkly Rep 2002; 51: 324.

14.- Barros M L, Boecken G. Jungle yellow fever in the central Amazon. Lancet 1996; 348: 969-70.

15.- McFarland J M, Baddour L M, Nelson J E, Elkins S K, Craven R B, Cropp B C, et al. Imported yellow fever in a United States citizen.
Clin Infect Dis 1997; 25: 1143-7.

16.- http://gamapserver.who.int/mapLibrary/Files/ Maps/ITH_YF_vaccination_americas.png (accedido agosto de 2011).

17.- http://new.paho.org/hq/index. php?option=com_docman\&task $=$ doc download\&gid=14598\&Itemid (accedido agosto de 2011).

18.- OPS. Área de Prevención y Control de Enfermedades. Unidad de Salud Pública Veterinaria. Consulta OPS/OMS de expertos sobre Rickettsiosis en las Américas: informe final. Ouro Preto, Minas Gerais, Brasil: OPS, Centro Panamericano de Fiebre Aftosa. 2004.

19.- Silveira I, Pacheco R C, Szabó M P J, Ramos H G C, Labruna M B. Rickettsia parkeri in Brazil. Emerg Infect Dis 2007; 13 (7): 1111-3.

20.- http://new.paho.org/hq/dmdocuments/2010/ alerta_epi_2010_22_junio_Fiebre_Oropouche. pdf (accedido agosto de 2011).

21.- http://new.paho.org/hq/dmdocuments/2010/ alertas_epi_2010_10_junio_fiebre_mayaro.pdf (accedido 20 de agosto de 2011).

22.- http://new.paho.org/hq/index.php?option=com docman\&task=doc_view\&gid=7597\&Itemid=1 091(accedido 28 de agosto de 2011).

23.- http://www.cdc.gov/parasites/chagas/(accedido 28 de agosto de 2011). 
24.- http://wwwnc.cdc.gov/travel/yellowbook/2012/ chapter-4-select-destinations/iguassu-fallsbrazilargentina.htm (accedido 3 de septiembre 2011).

25.- http://www.msal.gov.ar/dengue/partes/parte44. pdf (accedido 3 de septiembre de 2011).

26.- http://epi.minsal.cl/epi/html/bolets/reportes/ Dengue/Informedengue.pdf (accedido noviembre de 2011).

27.- http://new.paho.org/uru/index2. php?option=com_content\&do_pdf=1\&id=177 (accedido 3 de septiembre de 2011).

28.- Salomon O, Sinagra A, Nevot M, Barberian G, Paulin P, Estevez J, et al. First visceral leishmaniasis focus in Argentina. Mem Inst Oswaldo Cruz 2008; 103 (1): 109-11.

29.- Spinsanti L I, Díaz L A, Glatstein N, Arselán S, Morales M A, Farías A A, et al. Human outbreak of St. Louis encephalitis detected in Argentina, 2005. J Clin Virol 2008; 42 (1): 27-33.

30.- Seijo A, Morales A, Poustis G, Romer Y, Efron E, Vilora G, Lloveras S, et al. Brote de encefalitis de San Luis en el área metropolitana Buenos Aires. Medicina (Buenos Aires) 2011; 71: 211-7.

31.- Conti-Díaz IA. Rickettsiosis por Rickettsia conorii, fiebre botonosa del Mediterráneo: estado actual en Uruguay. Rev Med Uruguay 2001; 17: 119-24.

32.- Romer Y, Seijo A, Crudo F, Nicholson W, Varela-Stokes A, Nash R R, et al. Rickettsia parkeri rickettsiosis, Argentina. Emerg Infect Dis; 2011; 17 (7).

33.- Ripoll C M, Remondegui C E, Ordonez G, Arazamendi R, Fusaro H, Hyman M J, et al. Evidence of rickettsial spotted fever and ehrlichial infections in a subtropical territory of Jujuy, Argentina. Am J Trop Med Hyg 1999; 61: 350-4.
34.- Paddock C D, Fernández S, Echenique G A, Sumner J W, Reeves W K, Zaki S R, et al. Rocky Mountain spotted fever in Argentina. Am J Trop Med Hyg 2008; 78: 687-92.

35.- http://www.promedmail.org/pls/apex/f? $\mathrm{p}=2400: 1001: 2389045972620646::$ : :F2400_P1001_BACK_PAGE,F2400_P1001_ ARCHIVE_NUMBER,F2400_P1001_USE_ ARCHIVE:1001,20110808.2404,Y (accedido 6 de septiembre de 2011).

36.- http://www.medicinaysociedad.org.ar/ publicaciones/01_jun_2011/alerta\%20 HANTA\%20MAYO\%202011.pdf (accedido 6 de septiembre de 2011).

37.- http://wwwnc.cdc.gov/travel/yellowbook/2012/ chapter-3-infectious-diseases-related-to-travel/ viral-hemorrhagic-fevers.htm

38.- http://wwwnc.cdc.gov/travel/yellowbook/2012/ chapter-3-infectious-diseases-related-to-travel/ schistosomiasis.htm (accedido 6 de septiembre de 2011).

39.- Mutsch M, Tavernini M, Marx A, Gregory V, Lin Y P, Hay A J, et al. Influenza virus infection in travelers to tropical and subtropical countries. Clin Infect Dis 2005; 40: 1282-7.

40.- Leder K, Sundararajan V, Weld L, Pandey D, Brown J, Torvesi J, et al. Respiratory tract infections in travelers: a review of the GeoSentinel surveillance network. Clin Infect Dis 2003; 36: 399-406.

41.- Moura F E A, Perdiga o A C B, Siqueira M M. Seasonality of influenza in the tropics: a distinct pattern in northeastern Brazil. Am J Trop Med Hyg 2009; 81: 180-3.

42.- Ramírez A P, Mendoza A R, Montoya J M, Cótes K, López J D, Herrera D, et al. Mortality associated with peak seasons of influenza virus circulation in Bogota, Colombia, 1997-2005. Rev Panam Salud Pública 2009; 26 :
435-9.

43.- Laguna-Torres V A, Gómez J, Ocaña V, Aguilar P, Saldarriaga T, Chávez E, et al. (2009) Influenza-like illness sentinel surveillance in Peru. PLoS ONE 4(7): e6118. doi:10.1371/journal.pone.0006118.

44.- Douce R W, Aleman W, Chicaiza-Ayala W, Madrid C, Sovero M, Delgado F, et al. (2011) Sentinel surveillance of influenza-likeillness in two cities of the tropical country of Ecuador: 2006-2010. PLoS ONE 6 (8): e22206. doi:10.1371/journal.pone.0022206.

45.- http://wwwnc.cdc.gov/travel/yellowbook/2012/ chapter-3-infectious-diseases-related-to-travel/ tuberculosis.htm (accedido 6 de septiembre de 2011).

46.- Mattos-Guaraldi A L, Oliveira Moreira L, Vieira Damasco P, Hirata Júnior R. Diphtheria remains a threat to health in the developing world-An overview. Mem Inst Oswaldo Cruz, Rio de Janeiro 2003; 98 (8): 987-93.

47.- http://www.promedmail.org/pls/apex/f?p=2400: 1202:1053632275642438::NO::F2400_P1202_ CHECK_DISPLAY,F2400_P1202_PUB_ MAIL_ID:X,85080 (accedido 6 de septiembre de 2011).

48.- htpp://www.promedmail.org/pls/apex/f?p=2400: 1202:1053632275642438::NO::F2400_P1202 CHECK_DISPLAY,F2400_P1202_PUB MAIL_ID:X,88798 (accedido 6 de septiembre de 2011).

49.- http://wwwnc.cdc.gov/travel/yellowbook/2012/ chapter-3-infectious-diseases-related-to-travel/ hiv-and-aids.htm (accedido 6 de septiembre de 2011).

50.- http://wwwnc.cdc.gov/travel/yellowbook/2012/ chapter-2-the-pre-travel-consultation/foodpoisoning-from-marine-toxins.htm (accedido 6 de septiembre de 2011) 